\title{
Morphological structure of the tongue of the European badger (Meles meles)
}

\author{
A. Haligur ${ }^{1}(1)$, S. Ozkadif ${ }^{1}$, A. Alan², M. Haligur ${ }^{3}$ \\ 'Department of Anatomy, Ceyhan Veterinary Faculty, Cukurova University, Ceyhan-Adana, Turkey \\ ${ }^{2}$ Department of Anatomy, Veterinary Faculty, Erciyes University, Kayseri, Turkey \\ ${ }^{3}$ Department of Pathology, Ceyhan Veterinary Faculty, Cukurova University, Ceyhan-Adana, Turkey
}

[Received: 26 November 2020; Accepted: 27 January 2021; Early publication date: 1 March 2021]

Background: This study aimed to reveal the morphological aspects of the tongue and investigate the histologic and scanning electron microscopic (SEM) findings of the papillae on the tongue of the European badger.

Materials and methods: Two adult European badgers were used as material. The tongues of the European badgers were removed via the dissection method, and morphometric measurements were taken. The tongues were fixed in 10\% buffered formalin solution for histological examination, and the SEM procedure was applied to the tongues.

Results: Three types of papillae were observed on the tongues: filiform, fungiform, vallate papillae. The different shapes (hook or conical structures) of filiform papillae were observed on the whole tongue. Fungiform papillae were found scattered in filiform papillae. Six vallate papillae were found on the dorsal face of the middle and root of the tongues. In the root of the tongue, the lingual tonsil was observed in the lentiform shape.

Conclusions: The authors believe that this research will provide contributions to morphological knowledge about the tongue of the badger, which is a poorly known species. (Folia Morphol 2022; 81, 2: 394-399)

Key words: badger, morphology, papillae, scanning electron microscopic (SEM), wild animal

\section{INTRODUCTION}

The European badger (Meles meles) belongs to the order Carnivora of the Mustelidea subfamily and is found all around the world [3, 16]. The badger population in Turkey is endangered, and therefore these animals are protected through an international agreement with BERN and CITES [18].

The diet of the badger consists of larvae, pupae, and adults of different species of insects, as well as other small animals such as snails, frogs, reptiles, mice, and small rabbits. It consumes more herbal nutrients than other carnivore species. The badger uses its tongue similar to Carnivora [17].

Many studies have been conducted to investigate the tongue of different animals using scanning electron microscopic (SEM), histological, morphological or functional analyses. Among the animals investigated are the civet cat [19], silver fox [14], porcupine $[1,15]$, mice [21], Asian black bear and panther [5], bush dog [8], Japanese badger [24] and mongoose $[12,20]$. The aim of this study was to determine the possible scanning electron microscopic (SEM), histo-

Address for correspondence: Dr. S. Ozkadif, Department of Anatomy, Ceyhan Veterinary Faculty, Cukurova University, Ceyhan-Adana, Turkey, tel: +90 32261335 07, fax: +90 32261335 07, e-mail: semaerten80@gmail.com

This article is available in open access under Creative Common Attribution-Non-Commercial-No Derivatives 4.0 International (CC BY-NC-ND 4.0) license, allowing to download articles and share them with others as long as they credit the authors and the publisher, but without permission to change them in any way or use them commercially. 
logical and morphological changes in the papillae and tongue of the European badger. These results were compared with other studies in the literature to emphasize the morphologic and microscopic diversities among species. This study is also hoped to contribute to improving our current knowledge related to the badger.

\section{MATERIALS AND METHODS}

This study was performed with permission from the General Directorate of Nature Conservation and National Parks of the Ministry of Forestry and Water Affairs (permission number: 38002405-445.05177733). Also this study was accepted by the local Ethics Committee for animal experiments of the Cukurova University (decision number: 2017/6-5).

In this study, two dead adult European badgers (Meles meles) (2 females [9.21-11.72 kg]) were used as materials. This animals died by traffic accident in Ceyhan region. Classic dissection method was made and the tongue was removed from the head. Morphometric measurements were taken from the tongue by using a digital calliper. The methods used in tissue processing are described below.

\section{Histological procedure}

After the tongue of European badgers had been cleaned with physiological saline solution and examined anatomically, the appropriate sized parts of the tongue were fixed in $10 \%$ formaldehyde for 24 hours in order to preserve the tissue structure in the nearest living state and facilitate getting thin sections by increasing hardness. Tissue samples were washed to remove formaldehyde and passed through a series of low to high alcohol grades to remove water. After paraffin embedding, the blocks were cut transversely into $5 \mu \mathrm{m}$ sections and stained with haematoxylin and eosin (H\&E) for general histological examination. After staining, it was dehydrated by passing through alcohol series, cleared in xylene and mounted with entellan. The slides were examined histologically using light microscope (Lyca) and photographed with Lyca digital camera.

\section{SEM procedure}

First of all, trimmed specimens $(0.5 \times 0.5 \mathrm{~cm})$ were washed twice with $0.1 \mathrm{M} \mathrm{(pH} \mathrm{7.4)} \mathrm{phosphate} \mathrm{buffer}$ solution and then were kept in $2.5 \%$ glutaraldehyde solution for 2 days at $4{ }^{\circ} \mathrm{C}$. After that period, the tissues were kept in $1 \%$ osmium tetroxide $\left(\mathrm{OsO}_{4}\right)$ for
1 hour. The tissues were passed through sequential acetone series and dried with critical point drying. They were coated with gold by using Polaron SC7620 Sputter Coater and finally the images were taken with LEICA LEO 440 trade scanning electron microscopy in various magnifications.

\section{RESULTS}

\section{Morphological findings}

The tongue of the badger is elongated with an oval flat apex (Fig. 1). In this study, the tongue was examined in three parts: the tip, middle and root. The length of the tongue from the tip to the root was measured as $8.4 \mathrm{~cm}$ and $8.7 \mathrm{~cm}$. The thickness was $0.128-0.172 \mathrm{~cm}$ at the tip, $1.326-1.393 \mathrm{~cm}$ at the centre, and $1.667-1.701 \mathrm{~cm}$ at the root. The width of the tongue was $2.315-2.394 \mathrm{~cm}$ at the tip and $2.669-2.704 \mathrm{~cm}$ at the root. Accordingly, a significant expansion of the tongue was observed.

There were six vallate papillae on the tongue. The vallate papilla was seen as irregular; so, it was not in a $V$ shape. It was determined that the cranial first two of these papillae were prominent, and the last papillae was less pronounced. Especially in the middle part of the midline near the corpus, fungiform papillae were visualised in the external aspect. Filiform papillae were found along with the entire tongue. On both lateral sides of the tongue, it was seen that the shape of the filiform papillae changed in the caudal $1 / 3$ plane. In the caudal part of the tongue, filiform papillae were present but the number and shape were more pronounced and less in number than in the apex. Foliate papillae were not observed in any part of the tongue.

\section{Histological findings}

Filiform papillae were composed of stratified squamous epithelium (Fig. 2A). The dorsal surface of the papillae was observed to have prominent keratinisation structure. Fungiform papillae were observed among the filiform papillae (Fig. 2B). Conical and hook-shaped papillae were found in sections taken from the root of the tongue (Fig. 2C). These were localised between the filiform papillae. There were several taste buds covered with squamous epithelium (Fig. 2D). The top of the vallate papillae was seen to slightly collapse inwards, forming a wide encircling groove. The vallate papillae were found to be surrounded by several papillary projections. 


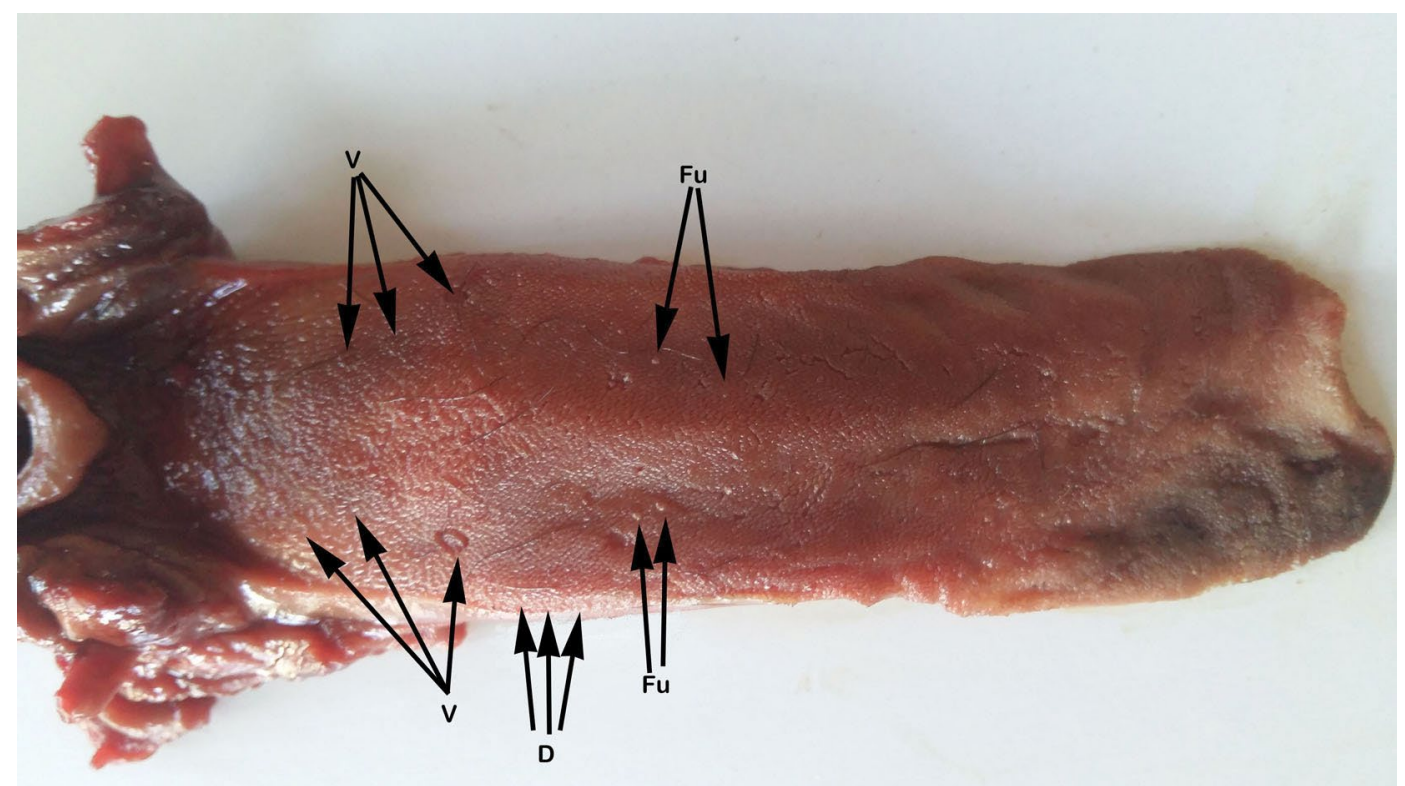

Figure 1. The general appearance of the dorsal surface of European badger tongue; D — differentiated filiform papillae; Fu — fungiform papillae, V - vallate papillae.
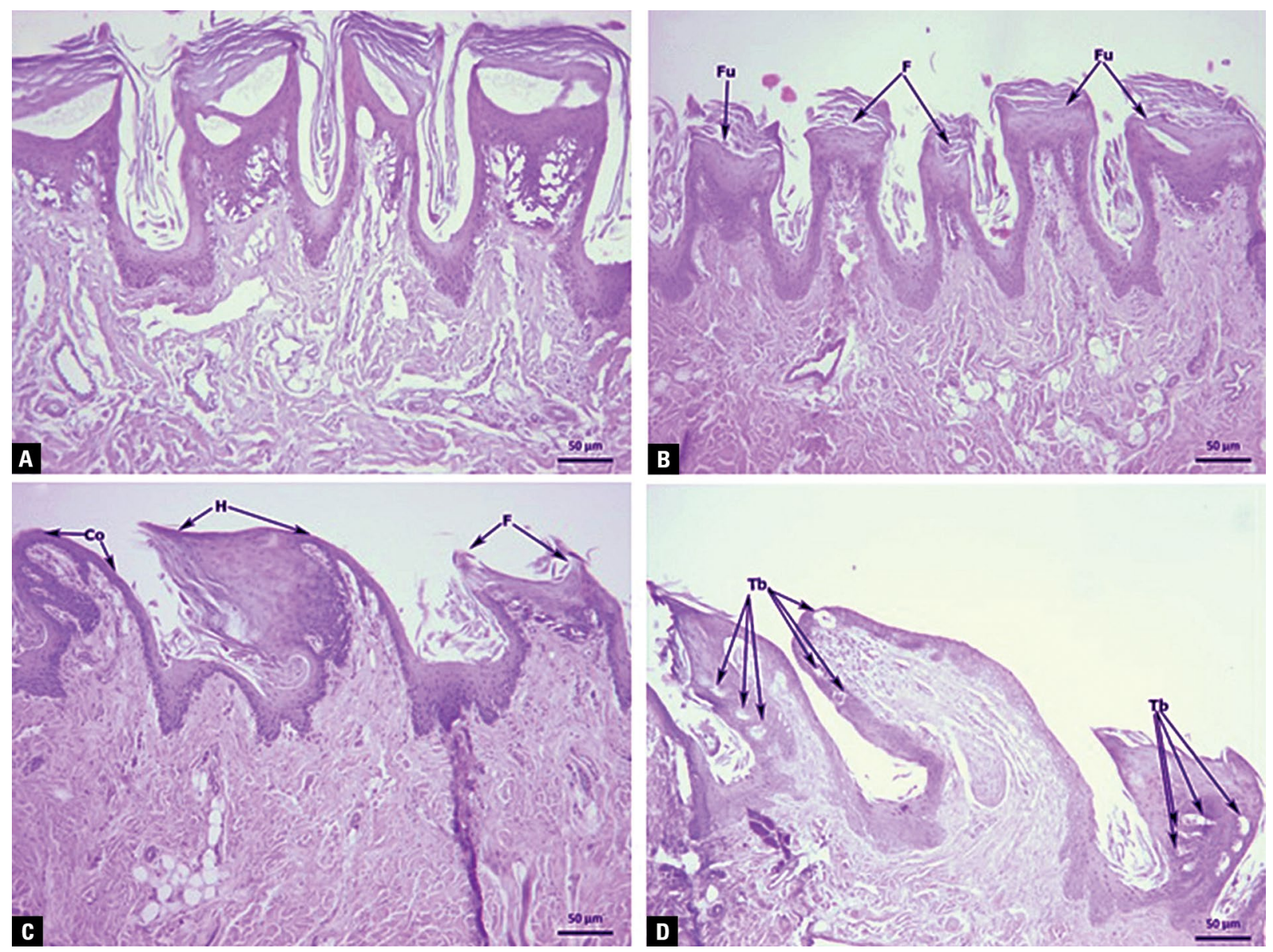

Figure 2. A-D. Histological sections of different regions of the tongue; $\mathbf{A}$. Filiform papillae in the apex tongue, $\mathrm{H} \& \mathrm{E}, \mathrm{bar}=50 \mu \mathrm{m} ; \mathbf{B}$. Fungiform and filiform papillae in the middle of the tongue; $\mathrm{F}$ - filiform papillae (arrows); $\mathrm{Fu}$ - fungiform papillae (arrows), H\&E, bar $=50 \mu \mathrm{m}$; C. Appearance of the different papillae on the root of the tongue; $\mathrm{Co}$ - conic papillae (arrows); $\mathrm{F}$ - filiform papillae (arrows); $\mathrm{H}$ - hookshaped papilla (arrow); H\&E, bar $=50 \mu \mathrm{m}$; D. Fungiform papillae on the middle tongue; $\mathrm{Tb}$ - taste buds (arrows), $\mathrm{H} \& \mathrm{E}, \mathrm{bar}=50 \mu \mathrm{m}$. 

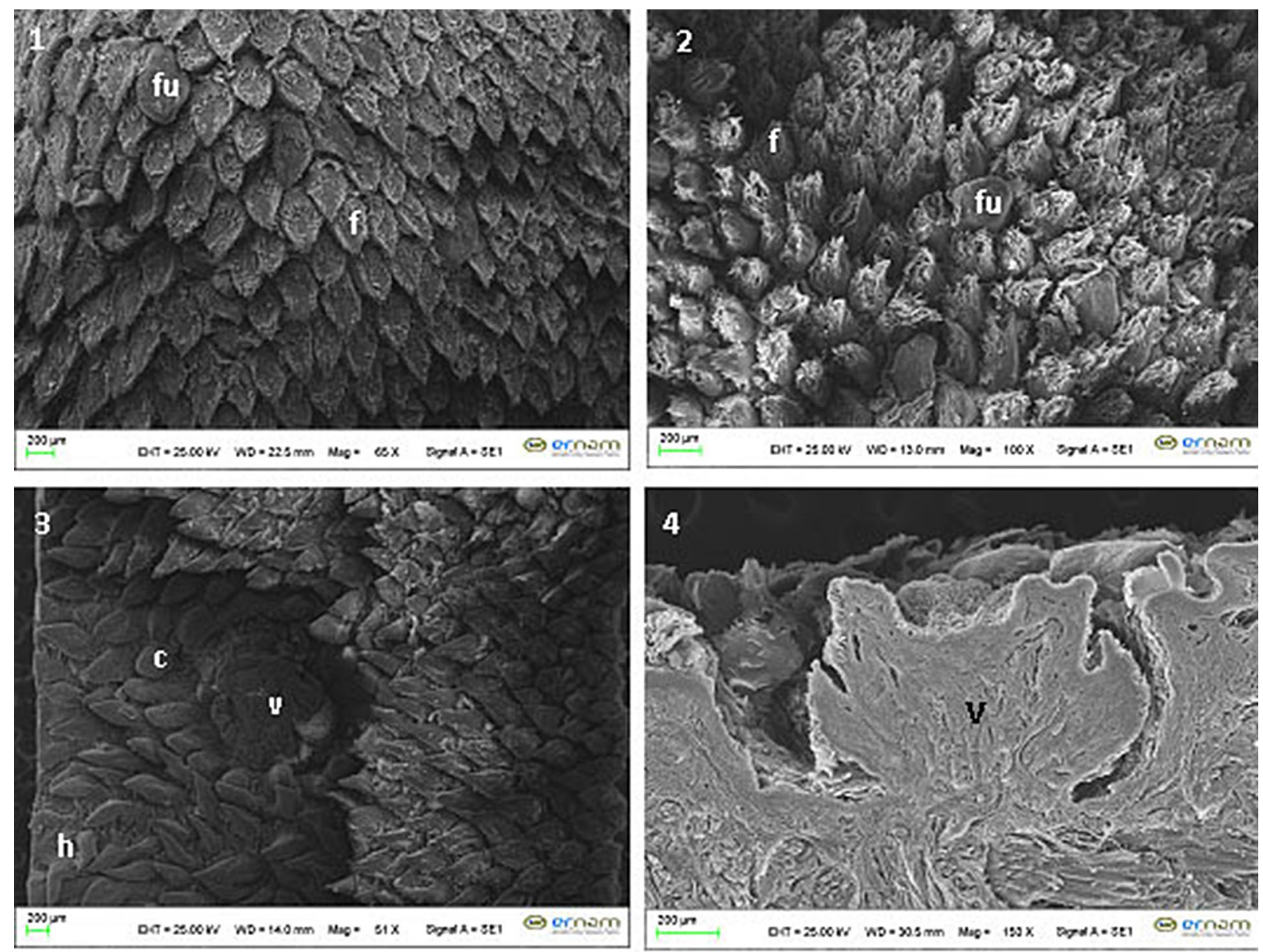

Figure 3. The tip of tongue and general appearance of the dorsal surface papillae; 1 . Localisation of the papillae fungiformes and scattered within the filiform papillae; $f u$ - fungiform papillae; $f$ - filiform papillae, SEM magnification $65 \times$, bar $=200 \mu$ m; 2 . General aspect of the middle of the tongue; fu — fungiform papillae; $\mathrm{f}$ - filiform papillae, SEM magnification $100 \times$, bar $=200 \mu \mathrm{m}$; 3. Marked vallate papillae and surrounding structure; $\mathrm{c}$ - conic papillae; $\mathrm{h}$ - hook shape papillae; $\mathrm{v}$ - vallate papillae; SEM magnification $51 \times$, bar $=200 \mu \mathrm{m}$; 4 . Longitudinal section of the vallate papillae; $v$ - vallate papillae, SEM magnification $150 \times$, bar $=200 \mu \mathrm{m}$.

\section{SEM findings}

In the SEM analyses of the tongues, the filiform (Fig. 3/1, 2-f), fungiform (Fig. 3/1, 2-fu) and vallate papillae (Fig. 3/3, 4-v) were identified. In addition to these main papillae, hook (Fig. 3/3-h) and conical papillae (Fig. 3/3-c) were seen on the dorsal surface of the European badger tongue.

The examination of the SEM images of both European badgers revealed that the dorsal surface of the filiform papillae of the middle was flattened. These papillae were observed to approach the caudal of the tongue, and looked like an arrow. The cranial part of the papillae was flat on the dorsal surface of the tongue. The number of filiform papillae was decreased toward the back of the tongue. However, these papillae were fewer than in the remaining parts of the tongue. In the same area, some of the filiform papillae were observed to have gland ducts.
Fungiform papillae were found scattered. Especially in the middle tongue, fungiform papillae were higher in number than filiform papillae, and they had an irregular ovoid shape. In addition, fungiform papillae were extensively located on the $1 / 3$ middle part of the tongue bilateral but they were not seen at the end of the tongue.

The vallate papillae were mostly found on the dorsal face of the middle and end of the tongue. A total of six vallate papillae were seen and four of these structures differed from the others. These four vallate papillae were faintly observed while the remaining two were marked. The top of the vallate papillae collapsed inwards, and their edges were fragmented. Papillae foliate were not observed, but the lateral edges of the tongue were differentiated in terms of filiform papillae, which did not contain a ductal structure. At the root of the tongue 


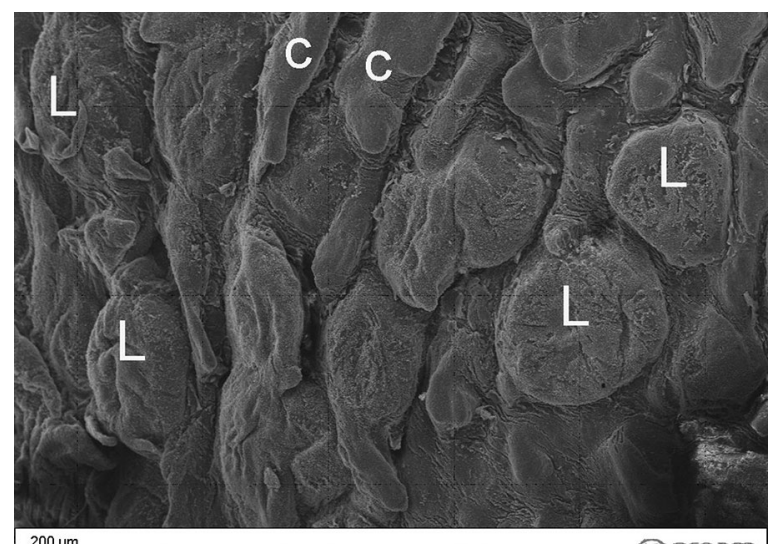

$200 \mu \mathrm{m} \quad \mathrm{EHT}=25.00 \mathrm{kV} \quad W \mathrm{WD}=24.0 \mathrm{~mm}$ Mag $=58 \mathrm{X}$ Signal $\mathrm{A}=$ SE $1 \Leftrightarrow \mathrm{ernJ \textrm {m }}$

Figure 4. General appearance of the dorsal surface of papillae and lingual tonsillae on the root of the tongue; $\mathrm{C}$ - conic papillae; $\mathrm{L}-$ lentiform structure of lingual papillae; SEM magnification $58 \times$, bar $=200 \mu \mathrm{m}$.

were lentiform-shaped structures of lingual tonsillae (Fig. 4). These structures were located under the epiglottis and arranged in a sequential " $U$ " shape.

\section{DISCUSSION}

The position of the papillae, structure, shape and length of the tongue vary among animal species. The length of the tongue was reported to be approximately $9 \mathrm{~cm}$ for young lions [22], 7-8 cm for the silver fox [14], raccoon dog and fox [7], $20 \mathrm{~cm}$ for tigers [6], 7-7.5 cm for the Japanese badger [24], $12.3 \mathrm{~cm}$ for pumas [11] and in 6-7 cm for porcupines $[1,15]$. In this study, the length of the European badger tongue was measured as $8.4-8.7 \mathrm{~cm}$. It was also found that the length of the tongue differed from the other species, which was considered to be due to the habitat.

In the silver fox [14], puma [11], tiger [6], young lion [22] and Carnivora [8, 13], the filiform papillae are found from the apex linguae to the radix linguae on the dorsal surface of the tongue. In addition, these papillae are seen on the ventral surface of the tongue, especially lateral edges, in the tiger [6], puma [11], young lion [22] and silver fox [14]. These papillae are located on the median channel of the dorsal surface of the tongue and have a similar shape to the hook of a meerkat [9]. These papillae have different types (bifurcated, papule-like, cylindrical, conical and blunt) in pumas [11]. In porcupines [15] they have two different shapes (one flat and the other cylindrical). On the margin of the tiger tongue, filiform papillae are divided into hemispherical, horny-shaped, giant club-shaped, conical, hoe-shaped or bifid types in the different parts of the tongue [6]. The current study was carried out with the European badger and revealed the presence of filiform papillae on the whole surface of the tongue (mostly at the tip and middle tongue). These papillae were similar both in terms of type and location to the meerkat [9], raccoon dog and fox tongue [7]. In the present study, another finding related to the filiform papillae was the presence of keratinized areas in these papillae, which is consistent with the finding reported by Selim and Samir [20]. In addition, unlike the Japanese badger [24], these papillae were detected in a small number in the root of the tongue (in hook, conic and filiform shapes). The epithelial structures of the filiform papillae in the European badger were similar to those of young lions [22].

In contrast to the literature $[6,20]$, in this study, the fungiform papillae were located in the posterior (tip) part of the tongue. Moreover, these papillae were generally observed on both sides of the middle part of the tongue. The shape of the fungiform papillae is reported to be flat at the upper surface in the silver fox [14], and smooth and dome-like in the Japanese badger [24]. These papillae are located on the apex and lateral region of the tongue and have a mushroom-like shape in squirrels [23] and a hemispherical or horn shape on the margin of the tongue in the tiger [6]. In this study, different from the literature $[2,10,14,23]$, the fungiform papillae were found to have an irregular ovoid shape, and were extensively observed after the $1 / 3$ middle part of the European badger tongue bilaterally. A few taste buds were found at the top of the fungiform papillae in the Japanese badger [24]. In this study, some of the buds were seen on both the upper and ventrolateral surfaces of the fungiform papillae as different from the Japanese badger [24].

The number of vallate papillae varies according to species; e.g. four for the silver fox [14] and puma [11], six for the civet cat [19] and Japanese badger [24], 7-8 for the Asian black bear and 5-9 for lion [4], 4 for tigers [6] and 28 for porcupines [1]. In the present study, the number of papillae was six as in the civet cat [19] and Japanese badger [24]. The vallate papillae are in a " $\mathrm{V}$ " shape in other species of animals; however, in the European badger, they were not regularly shaped, similar to the case observed in the raccoon dog and fox [7]. While the location of the papillae was similar to that of other animals, they had 
a different distribution. In addition, while the cranial first two filiform papillae were quite prominent, the others were not as pronounced in the European badger. This is another finding that differentiates the European badger tongue from the other animal species.

In the literature, it is that the civet cat [19] has two foliate papillae and from 4-5 laminas occur in silver fox [14]. Foliate papillae are not present in young lions [22], pumas [11] and tigers [6]. In this study, foliate papillae were not seen. The bilateral edges of the root tongue were similar to those of the Japanese badger [24] reported by Yoshimura.

\section{CONCLUSIONS}

In conclusion, this study shows that the number and position of papillae in the tongue of wild animals differ between wild species. The authors believe that the anatomic, histological and SEM findings of the data obtained from the present study will contribute to the literature.

\section{Acknowledgements}

This study was supported by Cukurova University Scientific Research Projects (Number: TSA-2017-8852).

\section{Conflict of interest: None declared}

\section{REFERENCES}

1. Atalar $\mathrm{O}$, Karan $\mathrm{M}$. The light and scanning electron microskopic structure of papilla vallatae in the porcupine (Hystrix cristata). J Anim Vet Adv. 2011; 10: 3069-3073, doi: 10.3923/javaa.2011.3069.3073.

2. Can M, Atalgin S, Ates S, et al. Scanning electron microscopic study on the structure of the lingual papillae of the Karacabey Merino sheep. Eur J Vet Sci. 2016; 32(3): 130-130, doi: 10.15312/eurasianjvetsci.2016318389.

3. Demirsoy A. Yasamın temel kuralları. Omurgalılar/Amniyota (sürüngenler, kuşlar ve memeliler) Cilt-III/Kısım-II. Meteksan, Ankara, Turkey 2003: 758.

4. Emura $\mathrm{S}$, Hayakawa $\mathrm{D}$, Chen $\mathrm{H}$, et al. and gross study on the lingual surface of the lion, Panthera leo. Mar Mammal Sci. 2003; 43(1): 45-50, doi: 10.11238/mammalianscience.43.45.

5. Emura $\mathrm{S}$, Hayakawa $\mathrm{D}$, Chen $\mathrm{H}$, et al. Morphology of the dorsal lingual papillae in the newborn panther and Asian black bear. Okajimas Folia Anat Jpn. 2001; 78(5): 173-177, doi: 10.2535/ofaj1936.78.5_173, indexed in Pubmed: 11915359.

6. Emura S, Hayakawa D, Chen $\mathrm{H}$, et al. Morphology of the lingual papillae in the tiger. Okajimas Folia Anat Jpn. 2004; 81(2-3): 39-43, doi: 10.2535/ofaj.81.39, indexed in Pubmed: 15455727.

7. Emura S, Okumura $\mathrm{T}$, Chen $\mathrm{H}$, et al. Morphology of the lingual papillae in the raccoon dog and fox. Okajimas Folia
Anat Jpn. 2006; 83(3): 73-76, doi: 10.2535/ofaj.83.73, indexed in Pubmed: 17154050.

8. Emura S, Tamada A, Hayakawa D, et al. Morphology of the dorsal lingual papillae in the bush dog (Speothos venaticus). Okajimas Folia Anat Jpn. 2000; 77(5): 137-141, doi: 10.2535/ ofaj1936.77.5_137, indexed in Pubmed: 11218710.

9. Erdoğan S, Lima M, Pérez W. Anatomical and Scanning Electron Microscopic Study of the Tongue in the Meerkat (Suricata suricatta, Schreber, 1776). Anat Histol Embryol. 2016; 45(1): 51-59, doi: 10.1111/ahe.12170, indexed in Pubmed: 25588707.

10. Erdoğan S, Pérez W. Anatomical and scanning electron microscopic studies of the tongue and lingual papillae in the chital deer (Axis axis, Erxleben 1777). Acta Zoologica. 2013; 95(4): 484-492, doi: 10.1111/azo.12044.

11. Erdoğan S, Villar S, König HE, et al. Papillary architecture of the lingual surface in the puma (Puma concolor). Anat Histol Embryol. 2018; 47(1): 51-57, doi: 10.1111/ ahe.12323, indexed in Pubmed: 29152772.

12. Iwasaki S, Miyata K. Fine structure of the dorsal epithelium of the mongoose tongue. J Anat. 1990; 172: 201-212.

13. Iwasaki S, Miyata K. Fine structure of the filiform papilla of beagle dogs. J Morphol. 1989; 201(3): 235-242, doi: 10.1002/jmor.1052010303, indexed in Pubmed: 2478716.

14. Jackowiak H, Godynicki S. The scanning electron microscopic study of lingual papillae in the silver fox (Vulpes vulpes fulva, Desmarest, 1820). Ann Anat. 2004; 186(2): 179-183, doi: 10.1016/s0940-9602(04)80037-2.

15. Karan M, Yilmaz S, Aydin A. Morphology of the filiform lingual papillae in porcupine (Hystrix cristata). Anat Histol Embryol. 2011; 40(2): 100-103, doi: 10.1111/j.14390264.2010.01045.x, indexed in Pubmed: 21105901.

16. Kuru M. Omurgalı hayvanlar. Palme, Ankara, Turkey 1999: 672.

17. Ozen AS, Ulucay I. Kütahya ili Meles meles Linnaeus, 1758 (Mammalia: Carnivora)'in bazı ekolojik, biyolojik ve taksonomik özellikleri. DPÜ Fen Bilimleri Enstitüsü Dergisi. 2010; 21: 9-20.

18. Pamukoglu N, Demir E. Porsuğun (Meles meles) Günlük Besinindeki Böcekler. Cent ent Stud Misc Pap. 2001; 74: 4-7.

19. Sarma K, Sarma M, Kalita SN. Gross anatomical and biometrical studies on the tongue of an adult small Indian civet cat. Isr J Vet Med. 2009; 64: 36-38.

20. Selim A, Samir R. Light and scanning electron microscope studies of the tongue of the egyptian mongoose (Herpestes ichneumon). J Cytol Histol. 2018; 9: 499, doi: 10.4172/2157-7099.1000499.

21. Toprak B. Light and scanning microscopic structure of filiform papillae in mice. Vet Arhiv. 2006; 76: 555-562.

22. Toprak B, Ulusoy Y. Macroscopic and light microscopic structure of lingual papillae on the tongue of a young lion (Panthera leo). Isr J Vet Med. 2011; 66: 114-117.

23. Unsaldi E. Sincaplarda (Sciurus vulgaris) Papillae Fungiformes'in Makroskobik ve Işık Mikroskobik Yapısı. Kafkas Univ Vet Fak. 2009, doi: 10.9775/kvfd.2009.530.

24. Yoshimura K, Shindo J, Kageyama I. Light and scanning electron microscopic study on the tongue and lingual papillae of the Japanese badgers, Meles meles anakuma. Okajimas Folia Anat Jpn. 2009; 85(4): 119-127, doi: 10.2535/ofaj.85.119, indexed in Pubmed: 19408581. 